\title{
FIRST-AID TREATMENT OF BURNS AND SCALDS
}

\author{
BY \\ LEONARD COLEBROOK, THOMAS GIBSON, AND J. P. TODD \\ From the Medical Research Council Burns Unit, The Royal Infirmary, Glasgow
}

In writing about the management of burns it is important to distinguish clearly between :

(a) Treatment applied as a purely temporary measure at the scene of the accident, before the patient is despatched to a hospital or doctor. This is strictly first aid.

(b) The formal treatment, carried out by a doctor or nurse, whether in the home, the surgery or the hospital, who has adequate facilities at his command. This we have termed, at the suggestion of Sir Almroth Wright, the plenary treatment, to convey the idea of completeness.

(c) Subsequent dressings, skin grafting procedures, etc.

The present paper is concerned only with first aid-and almost entirely with the local treatment of the burn. Civilian burns have been chiefly in mind, but the principles underlying treatment are the same for burns sustained on active service.

There is no agreed policy with regard to the initial treatment of burns. Owing to the urge to do something, however ill-advised, 75 per cent. of civilian patients arrive at hospital with some kind of application to the burned area-olive oil, flour, coagulant jellies, cold tea, sodium bicarbonate, an ' ointment,' or flavine, etc.-often covered with a dirty, or at least a non-sterile, piece of cloth.

Frequently pain has not been relieved by these applications-sometimes it has been increased; and the difficulty of removal of the semi-coagulated jelly, the oil or the caked flour, may well aggravate the original trauma suffered by the burned tissues, thereby favouring the development of shock.

First-aid remedies of this kind, especially if applied, as they usually are, without aseptic precautions, may well do much more harm than good.

In view of the great importance of burns in the mechanized warfare of to-day, and their contribution to wastage in industry, we have attempted to formulate a simple first-aid procedure which would be generally applicable, and have a satisfactory raison d'être.

Such an ideal first-aid procedure should :

(a) Relieve pain promptly and, by so doing, cut off sensory stimuli which probably play some part in inducing shock.

(b) Prevent the arrival of pathogenic organisms -in particular of haemolytic streptococcus-on the burned surface ; or, if this has already happened, destroy it or prevent its multiplication.

(c) Do no further damage to the already injured but viable skin tissues, nor interfere with the natural anti-bacterial defence by leucocytes.

(d) Be easily removed by gentle washing with a watery solution during the subsequent clean-up in hospital or the surgery.

\section{(a) Relief of Pain}

This was studied in two ways :

(1) By direct observation on small experimental burns on the human subject.

(2) By the application of creams containing analgesic agents to a series of accidental burns in factories and in the Burns Ward of the Royal Infirmary, Glasgow.

The experimental human burns were caused by a flat-bottomed copper tube through which water at temperatures of $55^{\circ}$ to $60^{\circ} \mathrm{C}$. was circulating (Leach, Peters and Rossiter, 1943). Light pressure with this tube on the forearm for 45-50 seconds gave a fairly uniform, manageable, second-degree burn, which was more painful than burns caused by higher temperatures for a shorter period.

Observations on some twenty-four of these standard low-temperature burns showed :

(i) That exposure to air caused pain and hot air increased it. The burned area is partially anaesthetic (prick test).

(ii) That cold water or any cold watery cream gave instantaneous relief (cooling effect), but this was usually short-lived and was followed by a variable amount of burning or throbbing which lasted for an hour or more.

(iii) The application of local analgesics in a cream composed of-

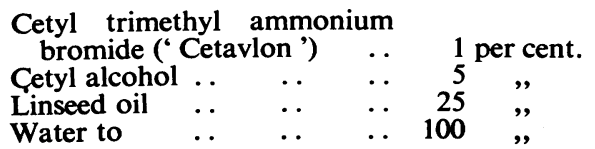

sometimes afforded more relief than the cream alone but the effect was not constant 
in different individuals. The local analgesics tested were :

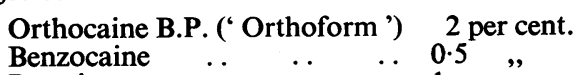
Percaine

The effect of these analgesic creams on accidental burns was similarly difficult to assess. At Messrs. Rolls-Royce, Ltd., the medical officer and his surgery staff were definitely of the opinion that the cream containing orthocaine was superior to those with other analgesics, and to the same cream without any analgesic. He also reported that very satisfactory healing, with almost no sepsis, resulted when this cream was left on the burns as the sole treatment. At another factory, Messrs. G. and J. Weir, Ltd., the medical officer and his assistants did not get such a clear-cut impression. In the Burns Ward at the Royal Infirmary the relief obtained from application of the orthoform cream was also somewhat variable. It was noted that many of the burns on arrival at hospital within half an hour to 2 hours did not complain of pain.

No toxic effects were observed from the use of these analgesics but they were not applied to extensive burns. We are informed by Lt.-Col. J. Barrett Brown, of the U.S. Army Medical Service, that such effects have been reported in America, particularly with percaine.

\section{(b) Preventing Infection}

One event is especially to be feared in connection with every fresh burn, namely, infection of the surface by the haemolytic streptococcus. If this does not occur the great majority of superficial burns heal within 7-20 days; if it does occur the damage to tissues is usually increased, healing may be much delayed, and, if the burned area involves flexures, contractures are likely to result.

In some cases a spreading cellulitis or lymphangitis may develop and constitute a threat to life. The late deaths (after the fourth day) are not infrequently due to such an invasive infection. Staphylococcal infection of the fresh burn may also be troublesome and delay healing, but seldom has such serious consequences as those due to streptococci.

Under the existing haphazard arrangements for first aid to burns both these infections are very common. Table 1 shows the incidence of streptococcal contamination of 516 burns on arrival at the Glasgow Royal Infirmary (1942-3). Within the first 12 hours after burning only 4 per cent. yielded haemolytic streptococci-and the proportion of positives was considerably lower for cases examined within 3 hours. After 12 hours the proportion of infected cases rises steeply.

$\begin{array}{ccc} & \text { TABLE 1 } & \\ \text { Number of } & \\ \text { bumber of hours } & \begin{array}{c}\text { burns } \\ \text { examined }\end{array} & \begin{array}{c}\text { Haemolytic strepto- } \\ \text { cocci present }\end{array} \\ \text { after injury } & 370 & 15=4.05 \text { per cent. } \\ 0-12 & 39 & 9=23.1 \\ 12-24 & 107 & 45=42.05,\end{array}$

Of all the minor burns treated as out-patients 30 per cent. were infected with haemolytic streptococci at their first visit to the hospital.

The primary object of all first aid to burns should be the prevention of these streptococcal infections. It should seek, in the first place, to prevent the arrival of any streptococci on the burned surfaces ; and, if they have already arrived there, it should seek to destroy them or at least to prevent their multiplication.

\section{How to prevent the arrival of Haemolytic 'Strepto-} cocci on the Burned Surfaces

Haemolytic streptococci are rarely found on. normal human skin (see below) ; and it follows, therefore, that those which infect burns must usually be derived from sources other than the patient's own skin.

Colebrook, Maxted and Morris Johns (1935) isolated haemolytic streptococci (group A) from only 7 of a group of 181 factory workers, and the circumstances suggested that in some of the 7 the organisms. might have come there from the respiratory tract. The same authors failed to isolate any group A strains from the perineum and thighs of 160 parturient women. Hare (1941) in Canada isolated only one group A strain from the hands of 248 students. Colebrook (1930) also showed that when haemolytic streptococci were experimentally dried on the skin of the hands they did not remain viable for more than a few hours.

It is not difficult to visualize the many sources from which burns may acquire these infecting cocci. Haemolytic streptococci are widely distributed in all human communities of the temperate zones, being associated with, and continually disseminated from, many common infectious processes, e.g. cellulitis and septic sores, erysipelas, impetigo, whitlows, scarlet fever and tonsillitis, otitis media and chronic ' running ears' of childhood, puerperal fever. etc. In addition they are present in the nasopharynx of many healthy carriers (5-30 per cent. of the population) who project them into their environment by coughing, sneezing, etc. Less commonly they proliferate in the nose of nasal carriers, and these individuals are especially dangerous because of the continual seepage on to handkerchiefs, clothes, hands, etc. From all these sources haemolytic streptococci find their way into the air of public places and private houses; they remain viable for long periods in dust and are freely disseminated by the sweeping of floors and the shaking of blankets and other bedding. (Thomas, 1941; Colebrook et al. 1944.)

Finally, it should be noted that, although haemolytic streptococci cannot survive in the acid secretion of normal skin, they multiply very rapidly in the serous exudate of burned surfaces and commonly persist there for long periods.

Clearly it will not be easy to prevent the fresh burn from contamination from so many potential sources; and without strict precautions first-aid 
procedures may themselves provide the medium for such contamination. There can be little doubt that in the past they have often done so.

First-aid personnel should wear efficient masks covering the mouth and nose, or, if these are not available, a clean handkerchief will serve. The burned surface should be covered as soon as possible with a sterile cloth or at least a recently laundered clean towel. Blankets are seldom sterilized at the laundry and therefore are very apt to be contaminated with pathogenic organisms, including haemolytic streptococci. They should on no account be allowed to touch the burned surface.

The hands of first-aid personnel should be carefully washed for at least 2 minutes, and then dried on a clean towel, before any treatment of the burn is undertaken.

If the burn is extensive and cannot be exposed without removal of clothes, the patient should be sent straight to hospital without any first-aid dressing of the surface.

\section{How to deal with Haemolytic Streptococci which have already arrived on the Burned Surface}

First aid should include a minimum of interference with the burned surface because the conditions will seldom be such as to allow of strictly aseptic procedure. For this reason the burn should not be washed nor should blisters be snipped.

The bactericidal or bacteriostatic agent employed should be in the form of a water-soluble cream which can be easily washed off during the subsequent plenary treatment, rather than a jelly or coagulant solution, such as tannic acid, which will be difficult to remove. Bactericidal dyes, like gentian violet, although they may have advantages in some special circumstances, e.g. on small ships, are not recommended for general use because they prevent the medical man who subsequently treats the case from forming any opinion as to the depth of the burn. They are also highly toxic to the already injured skin tissues, and cannot be washed off during plenary treatment. They cannot be relied upon to sterilize the burned surface with certainty.

Of the anti-bacterial agents available at present the new synthetic detergent, cetyl trimethyl ammonium bromide ('Cetavlon') seems likely to be the most effective for the first-aid treatment of burns. Barnes (1942) showed that, in addition to its cleansing effect on normal skin, it was remarkably effective in getting rid of 'resident' organismsapparently reaching those in the depths of sweat and sebaceous glands and hair follicles more successfully than the substances previously employed as skin antiseptics. Our own experiments and those of Williams et al. (1942) have confirmed this, and also the fact that Cetavlon has a rapidly lethal action on haemolytic streptococci. Because of its toxic action on leucocytes and tissue culture cells (Barnes, 1942; Jacoby, 1943) it cannot be regarded as the ideal substance to apply to tissues which we want to regenerate, but in actual practice with burns the risk of any toxic effect has proved very slight. Apart from three instances of sensitization-dermatitis (see note below) no irritant effects have been observed among the two thousand burns to which Cetavlon has been applied in Glasgow during 1942-3 ; nor has it seemed to delay healing.

Cetavlon also has the disadvantage of being a potent protein precipitant, and thereby forfeits much of its anti-bacterial potency in presence of the serous exudate of burns. As shown in Table 2, however, this anti-bacterial effect is by no means abolished by serum or blister fluid. Pending the discovery of an equally potent anti-bacterial substance which is free from these defects Cetavlon appears to be the most suitable one for the firstaid application to burns. By virtue of its powerful detergent properties it will remove most of the detachable organic material from the burned surface and surrounding skin, and thereby greatly facilitate the destruction of bacteria. It is, moreover, not incompatible with sulphonamides, so that these two anti-bacterial agents can be combined in a firstaid cream.

Such a combination seemed desirable for two reasons: (1) because the bacteriostatic effect of the sulphonamide would reinforce that of the Cetavlon, and (2) because sulphonamide was likely to be more effective than Cetavlon in controlling an infection by haemolytic streptococci which had already invaded the tissues, e.g. in burns several hours old when first seen.

Several such combined creams were prepared for trial at the Glasgow Royal Infirmary by one of us (J. P. T.). The most satisfactory one ('No. 9 Cream ') had the following composition :

Cetyl trimetyhl ammonium bromide Sulphanilamide. Castor oil

Beeswax

Wool fat

Cetyl alcohol

Glycerin. .

Water...

$\begin{array}{ccc}\ldots & 1 & \mathrm{gm} . \\ \ldots & 10 & , \\ \ldots & 25 & , \\ \ldots & 1 \cdot 8 & , \\ \ldots & 1 \cdot 8 & , \\ \ldots & 5 & , \\ \ldots & 10 & , \\ \ldots & 45 \cdot 4 & ,\end{array}$

It is prepared as follows: Melt the castor oil, beeswax, wool fat and cetyl alcohol at as low a temperature as possible. Dissolve the Cetavlon in the water with the aid of heat and mix with the oil, etc., at about $60^{\circ} \mathrm{C}$. and stir till set. The sulphanilamide is then rubbed up with an equal weight of glycerin, the two together comprising 20 per cent. of the final product. This sulphanilamide-inglycerin is then incorporated in the cream and

* Recent batches of No. 9 Cream have contained only 3 per cent. of sulphanilamide. This reduction was decided upon when it was found that a toxic dose of the drug may sometimes be absorbed from extensive burns dressed with the 10 per cent. cream. (Contrary to our expectations this excessive absorption occurred in patients with deep, heat-tanned burns rather than in second-degree burns.) Excessive absorption from a 3 per cent. cream would be very unlikely Even if as much as $300 \mathrm{gm}$. were used for a single application it would contain only $9 \mathrm{gm}$. Of sulphanilamide. Only part of this would be absorbed, and its absorption would be spread over severa hours; part would seep away into the dressings after solution in the exudate; and some would probably remain undissolved. On the enough to give the desired prophylactic effect. 
thoroughly mixed. A Peerless Mixer with bent arm at slow speed has given the best results, but it is quite possible to make the preparation by hand, although not quite so well.

(NoTE.-This cream cannot be heated to sterilize it, but it can be regarded as self-sterilizing for the ordinary non-sporing pathogens. Samples experimentally contaminated with staphylococcus aureus, B. proteus and Ps. pyocyanea have always been found free from viable organisms after 24 hours. It is possible that spores of pathogenic clostridia, including tetanus, might survive in it (this point is being investigated), but the risk of such contamination may be regarded as extremely small. When the cream is to be kept for long periods chlorocresol $(0.2$ per cent.) should be added to it to prevent any growth of moulds.)

\section{In vitro Tests with No. 9 Cream and other First-Aid Remedies in common use}

To find out how much bactericidal or bacteriostatic effect was to be expected in the presence of a copious exudate of blister fluid on the surface of a burn, tests were carried out as follows:

1 c.c. volumes of blister fluid (if available), or of serum, were inoculated with staphylococci and haemolytic streptococci, and then vigorously shaken with a large loopful (40 mg. approx.) of the cream or other first-aid remedy. Viable counts were made (with adequate dilution but without chemical neutralization of the bactericidal agent) before the addition of the test substance, and again after 24 hours incubation with it at $37^{\circ} \mathrm{C}$. Typical results are shown in Table 2 :

It is seen that:

(a) In blister fluid alone staphylococcus aureus and haemolytic streptococcus multiplied freely. (This is not the case with some of the non-pathogenic ' micrococci' normally resident on the skin.) (b) In presence of No. 9 Cream and the dyejellies used these organisms were killed off.

(c) In presence of tannic acid, phenol had not any antiseptic action, while acriflavine also was largely neutralized, allowing staphylococcus to grow out, although streptococcus did not.

By this test No. 9 Cream appears at least as satisfactory as the jellies containing bactericidal dyes, and it has the important practical advantage over these that it can be readily washed off for the plenary treatment, allowing the medical man to estimate the depth of the burn.

It is recognized that these in vitro tests as performed do not reflect exactly what would happen on the surface of a fresh burn, because they take no account of any fixation of the antiseptic agent by the tissue cells of the burned surface. Other observations, which will be reported elsewhere, showed that washing over a fresh burn (i.e. not more than 24 hours old) with Cetavlon solution did usually reduce the bacterial contamination of the surface from a matter of 'thousands' to nil or almost nil. We think it may be presumed that a similar effect will be obtained with No. 9 Cream.

\section{Clinical Trials of First-Aid Creams}

Following upon these tests in the laboratory observations were made upon two series of minor burns attending Glasgow Royal Infirmary in order to determine if possible how far the application of the creams was preventing infection by haemolytic streptococci.

Series I. Two creams were used, viz. No. 9 as described above, and a simpler one, 'Cetavlon Cream,' containing no sulphanilamide. Its composition was: cetyl trimethyl ammonium bromide 1 gm., cetyl alcohol 5 gm., linseed oil 25 gm., water $69 \mathrm{gm}$.

\begin{tabular}{|c|c|c|c|c|}
\hline & \multicolumn{2}{|c|}{ Staphylococcus aureus } & \multicolumn{2}{|c|}{ Haemolytic streptococcis } \\
\hline & $\begin{array}{c}\text { Before } \\
\text { incubation }\end{array}$ & $\begin{array}{c}\text { After } \\
\text { incubation }\end{array}$ & $\begin{array}{c}\text { Before } \\
\text { incubation }\end{array}$ & $\begin{array}{c}\text { After } \\
\text { incubation }\end{array}$ \\
\hline 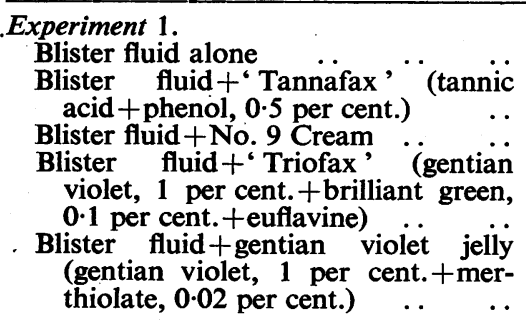 & $\begin{array}{l}80,000 \\
80,000 \\
80,000 \\
80,000 \\
80,000\end{array}$ & $\begin{array}{c}18,000,000 \\
2,000,000 \\
0\end{array}$ & $\begin{array}{l}19,000 \\
19,000 \\
19,000 \\
19,000 \\
19,000\end{array}$ & $\begin{array}{c}13,000,000 \\
600,000 \\
0\end{array}$ \\
\hline 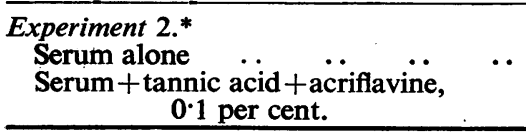 & $\begin{array}{l}300,000 \\
300,000\end{array}$ & $\begin{array}{r}10,000,000 \\
2,000,000\end{array}$ & $\begin{array}{l}150,000 \\
150,000\end{array}$ & $\begin{array}{c}15,000,000 \\
0\end{array}$ \\
\hline
\end{tabular}

* In this experiment No. 9 Cream, 'Triofax' and gentian violet jelly gave the same result as in experiment 1. 
Consecutive cases (not severe enough for admission) were treated as follows at their first attendance: A moist swab (A) was rubbed over the burned surface for subsequent bacteriological examination. Blisters, if present, were not opened nor epithelial debris removed; nor was any attempt made to clean up the burned surface in order to remove the substances previously applied-caked flour, vaseline, semi-coagulated jellies, etc. After being dressed with one of the two creams, covered with gauze, wool and a bandage, the patient was told to report next day at the out-patient burns clinic. Here a second swab (B) was taken for bacteriological examination, and the burn then received its full or plenary treatment *-blister skin being removed, the surface gently cleaned with Cetavlon solution and a sulphanilamide dressing applied. Eighty-two patients were treated in this way with Cetavlon cream and sixty-two with No. 9.

The clinical results of these trials were very satisfactory-the dressings having been comfortable from the first in the great majority of cases, and the burned surfaces either healed or almost healed when the patients came back after one week.

The bacteriological evidence as to the control of infection is shown in Table 3 :

TABLE 3

Group 1. Cases in which cream Cetavlon No. 9 was applied within 24 hours Cream Cream of the injury. Total 119

Did not become infected with H.S. (haemolytic streptococcus)

H.S. present in first and second swabs .. . . . . ..

H.S. present in first swab but did not persist

Became infected with H.S. after application of cream

\begin{tabular}{rr}
$\cdots$ & $4 \ddagger$ \\
\hline 72 & 47
\end{tabular}

Group 1a. Cases belonging to Group 1, but in which the second swab was taken more than 24 hours after injury. Total 68

Became infected with H.S. after application of cream in which

Approximate number in which pected after 24 hours (see Table 1) if cream had not been applied. $4+$

66

$$
2 \dagger
$$

42

roup 2. Cases to which cream was applied 24 hours or more after the injury. Total 25

Did not become infected with

H.S. . . . 6

* It should be made clear that the above procedure was adopted only to obtain evidence as to its efficacy in preventing infection by streptococcus. If this object had not been in view the plenary

$t$ Of these 6 cases, 3 had been burned 21 hours or mospital. $t$
Of these 6 cases, 3 had been burned 21 hours or more before the cream was applied, so that invasion of the tissues had probably begun. flour, which may have prevented effective contact of the cream.
TABLE 3-continued

\begin{tabular}{|c|c|c|}
\hline \multirow{4}{*}{$\begin{array}{l}\text { H.S. present in first and second } \\
\text { swabs .. } \\
\text { H.S. present in first swab but } \\
\text { did not persist } \\
\text { Became infected with H.S. after } \\
\text { application of cream }\end{array}$} & $\begin{array}{c}\text { Cetavlon } \\
\text { Cream }\end{array}$ & $\begin{array}{l}\text { No. } 9 \\
\text { Cream }\end{array}$ \\
\hline & (2) & $8 * *$ \\
\hline & 0 & 0 \\
\hline & $2+\dagger$ & $1 \S$ \\
\hline & 10 & $15^{\circ}$ \\
\hline
\end{tabular}

The data in Table 3 suggest the following tentative conclusions:

(1) That temporary dressing of the burns with cream in the 68 cases of group la did to some extent prevent their becoming infected with haemolytic streptococci. In view of the figures in Table 1, it seems reasonable to suppose that many more than 4 of these 68 cases would have been so infected after 24 hours if they had been left alone. (It must, however, be admitted that any sterile dressing would have had some protective effect.)

(2) That the creams used were not usually successful in getting rid of the haemolytic streptococci already present on the burned surfaces at the time of the first swab. The failure to get rid of them in 6 cases out of 7 should, however, be viewed in the light of footnote. $\uparrow \quad$ It may well be that we should have had more success if all the cases had been burned only a short time and if the burns had not been smeared with 'white ointment,' vaseline, jellies, etc., before the cream was applied. The failure to eliminate haemolytic streptococci from burns to which our creams were applied late, i.e. more than 24 hours after injury, did not surprise us, because Barnes had previously shown that Cetavlon did not reduce the bacterial count of a granulating surface, and our own experience with definitely infected burns had confirmed this many times. Once the streptococci have invaded the tissues Cetavlon is probably of little or no use.

Series II. In this series of 104 minor burns only No. 9 cream was used and the procedure was modified slightly in the hope that we should get still better control of infection. The various applications made before coming to hospital were removed as far as possible; a swab (A) was then taken for bacteriological examination; blisters were usually emptied (but blister skin not cut away); the burned areas were then washed over with Cetavlon solution, and No. 9 cream applied for periods varying from 12 to 48 hours. The second swab (B) was then taken and the usual plenary treatment applied.

Seventy-three cases were free from streptococci when they first came to the hospital (A swab) and none had acquired them when the B swab was taken 20-40 hours later-with two exceptions, for which there was a sufficient explanation. One of these

** These patients had been burned respectively 27 hours, 2 days ( 2 cases), 3 days ( 2 cases), $3 \frac{1}{2}$ days, 5 days and 7 days.

$\left(2\right.$ cases), 3 days ( 2 cases), $3 \frac{1}{2}$ days, 5 days and 7 days. t† One of these burns was covered with ointment, the other had a satisfactory contact of the cream.

$\&$ This is open to doubt; the first swab gave a confluent growth of $\$$ This is open to doubt; the first swaly streptococcal colonies staphylococcus in which a detection. 
was a boy who did not reappear for 7 days after the first-aid treatment was applied; the other, a child which pulled off its dressing before it came back for the second swab.

Of the 31 patients who already had haemolytic streptococci in the A swab, 8 had lost them before the second swab was taken-presumably as a result of the first-aid treatment. Of the remaining 23 patients, who did not lose their streptococci, 20 had been burned more than 24 hours before they came to hospital and 2 of the others were burned 16 and 20 hours respectively before treatment.

These results certainly suggest that the cream and the Cetavlon solution were effective in holding off streptococcal infection in this series of burns.

\section{Commentary upon these Clinical Trials}

1. We do not claim to have proved conclusively that the first-aid procedures adopted have prevented infection by streptococci, although we think that the findings point to a large measure of success and warrant a more extended trial of the methods.

2. A random series of hospital patients, some of whom have been burned many hours or even days before, and have had divers applications, cannot yield clear-cut results. Future comparative trials of first-aid remedies should be made on fresh burns which have had no previous treatment.

3. Medical officers of large industrial organizations, e.g. foundries where many minor burns occur, in collaboration with a bacteriological laboratory, could obtain valuable data by comparison of cases treated with No. 9 or other antiseptic cream, with other cases treated with the same cream without the antiseptic.

\section{Note on Sensitization to Cetavlon}

In the course of this work we have encountered three instances of severe vesicular dermatitis apparently induced by the application of Cetavlon. In two of these the condition developed after the Cetavlon cream had been in contact with the burned areas for several days (12 days in one case); in the remaining case the solution of Cetavlon had been applied to the skin on only three occasions and the dermatitis developed 7 days after the third application. In all three the condition cleared up within 2-3 weeks, after becoming more or less generalized and associated with some degree of toxic disturbance. A scratch test with a 1.5 per cent. solution of Cetavlon gave a definite positive result in all three cases after the dermatitis had cleared up. A similar test with potassium bromide in two of the cases gave a negative result. Potassium bromide by mouth in one case produced a slight eruption.

One of the patients has had two recurrences of the dermatitis at intervals of several months-one of them definitely induced by accidental contact with Cetavlon.

These three are the only cases of dermatitis we have met in a total of more than 2000 burns to which Cetavlon has been applied at the Glasgow Royal Infirmary. We are informed by Dr. R. G.
MacFarlane that a 1 per cent. solution has been used for cleansing the skin of some 2160 blood donors in the West of England and that no dermatitis has been reported to date.

\section{Conclusions}

1. The avoidance of infection by haemolytic streptococcus should dominate first-aid policy for all but very severe burns. In the latter, measures for the preservation of life will often have to take precedence over local treatment of the burn.

2. For most small burns which are accessible, e.g. of the hand or forearm or head, first aid at the scene of the accident should usually be limited to covering with a recently laundered clean towel, or, better, if it is available, with a sterile cloth. (Wherever burns are likely to occur such cloths should be kept ready, previously sterilized in an oven and stored in a tin.) The burn thus covered should be sent at once to the factory surgery, or a hospital, or a private doctor.

In all severe or extensive burns no first aid should be attempted other than keeping the patient warm and giving morphia if required. Immediate removal to hospital is the first consideration.

3. When quite superficial small burns are treated at home or when, in the case of more severe burns, the plenary treatment cannot be carried out without considerable delay, it is recommended that the burned area, and the skin around, should be freely smeared with a water-soluble cream containing 1 per cent. of cetyl trimethyl ammonium bromide ('Cetavlon') and 3 per cent. of sulphanilamide. This cream should be applied with a knife blade or spoon, previously sterilized by dipping for 2 minutes in boiling water. The burn should not be washed before the cream is applied nor should blisters be snipped.

This first-aid treatment must be carried out with due precautions against the transfer of streptococci to the burned surface. Thus, the operator's hands must be thoroughly washed and dried; and he should wear a gauze mask or a clean handkerchief over his mouth and nose.

After smearing with the cream the burn should be carefully wrapped in sterile lint and a bandage, or in a recently laundered clean towel.

On no account should blankets be allowed to come into direct contact with the burn (because they are frequently heavily contaminated with pathogenic organisms).

4. The cream should not as a rule be left on the burn for more than 2 days because there is a slight risk of inducing dermatitis if left longer.

In special cases, e.g. in a small ship, or in shipwrecked persons, this small risk will be of no account in comparison with the much greater risk of infection if the burn is not treated.

5. The inclusion of a local analgesic in the firstaid cream is not recommended-for the following reasons:

(a) It is unlikely to give sufficient relief for a severe burn, which will usually require morphia. 
(b) The pain of many small burns is so transient as to need no analgesic.

(c) The relief of pain by local analgesics is uncertain, and often short-lived.

(d) There is some risk of toxic effects from the use of local analgesics on a large burned area in susceptible individuals.

\section{Acknowledgements}

Our thanks are due to Mr. A. M. Clark, in whose Department this work was carried out; and to Dr. M. L. Thomson, Mr. W. C. Cawston, Sister Donald and Sister Bertram, who undertook much of the routine work; to Dr. A. Tracy and the volunteers collected by him who submitted to experimental burning; and to Dr. E. Collier who helped in the clinical trials of local analgesics.
In connection with this work one of us (T. G.) received a special grant from the Medical Research Council.

\section{REFERENCES}

Barnes, J. (1942). Lancet, I, 531.

Colebrook, L. (1930). Ministry of Health; Appendix to Interim Report of Committee on Maternal Mortality and Morbidity.

- - Clark, A. M., Gibson, T., and Todd, J. P. In the Press.

-_, Maxted, W. R., and Morris Johns, A. (1935). J. Path. Bact., 41, 521.

Hare, R. (1941). Lancet, I, 85.

Jacoby, F. (1943). J. Physiol., 102.

Leach, E. H., Peters, R. A., and Rossiter, R. J. (1943). Quart. J. exp. Physiol., 32, 67.

Thomas, J. C. (1941). Lancet, I, 433

Williams, R., Clayton-Cooper, B., Duncan, J. McK., and Miles, E. (1943). Ibid., I, 522. 